\title{
Control of tick infestations in wild roe deer (Capreolus capreolus) vaccinated with the Q38 Subolesin/Akirin chimera
}

\author{
Marinela Contreras $^{\mathrm{a}, *}$, Cristina San José ${ }^{\mathrm{b}}$, Agustín Estrada-Peña ${ }^{\mathrm{c}}$, Ventura Talavera ${ }^{\mathrm{b}}$, Elena Rayas ${ }^{\mathrm{b}}$, \\ Clara Isabel León ${ }^{\mathrm{b}}$, José Luis Núñez ${ }^{\mathrm{d}}$, Isabel García Fernández de Mera ${ }^{\mathrm{e}}$, José de la Fuente ${ }^{\mathrm{e}, \mathrm{f}}$ \\ a Interdisciplinary Laboratory of Clinical Analysis of the University of Murcia (Interlab-UMU), University of Murcia, Espinardo, Spain \\ ${ }^{\mathrm{b}}$ Junta de Andalucía. Agencia de Medio Ambiente y Agua de Andalucía. Consejería de Agricultura, Ganadería, Pesca y Desarrollo Sostenible \\ ${ }^{c}$ University of Zaragoza. Faculty of Veterinary Medicine \\ d Delegación Territorial de Cádiz. Consejería de Agricultura, Ganadería, Pesca y Desarrollo Sostenible. Junta de Andalucía, Cádiz, Spain \\ e SaBio, Instituto de Investigación en Recursos Cinegéticos IREC-CSIC-UCLM-JCCM, Ciudad Real, Spain \\ ${ }_{\mathrm{f}}^{\mathrm{f}}$ Department of Veterinary Pathobiology, Center for Veterinary Health Sciences, Oklahoma State University, Stillwater, OK, United States
}

\section{A R T I C L E I N F O}

\section{Article history:}

Received 12 May 2020

Received in revised form 14 July 2020

Accepted 28 July 2020

Available online $\mathrm{xxxx}$

\section{Keywords:}

Akirin

Subolesin

Tick

Vaccine

Roe deer

Immunology

\begin{abstract}
A B S T R A C T
Ticks (Acari: Ixodidae) are considered to be the most important vectors of disease-causing pathogens in domestic and wild animals, and emerging and re-emerging tick-borne diseases (TBD) exert an enormous impact on them. Wild ungulates are hosts for a wide variety of tick species and tick-borne pathogens that affect human and animal health. Consequently, the control of tick infestations and tick-borne pathogen prevalence is essential in some regions. Acaricides and animal management or culling have been used for the control of tick infestations and TBD, but tick vaccines constitute the best alternative to reduce the impact of acaricides on tick resistance and the environment. Previous results of controlled vaccination trials have shown that the Q38 Subolesin/Akirin chimera containing conserved protective epitopes could be a candidate universal antigen to control multiple tick species infestations. Thus, vaccination trials are necessary to validate these results under field conditions. In this study, we characterized the effect of Q38 vaccine on a wild population of European roe deer (Capreolus capreolus) in the Andalusian roe deer Reference Station (Junta de Andalucía, Cádiz, Spain). In this location, roe deer suffer especially severe parasitic conditions in some periods and commercial pesticides and ixodicides that are authorized to control ticks without specificity are frequently applied in the field, posing a threat to the environment. Animals vaccinated over a three-year period showed an antibody response to the vaccine antigen and a reduction in tick infestations by multiple species including Hyalomma marginatum, H. lusitanicum, Rhipicephalus bursa and Ixodes ricinus previously identified in roe deer, when compared to untreated controls. These results suggest the efficacy of Q38 for the control of tick infestations in wildlife.
\end{abstract}

() 2020 Elsevier Ltd. All rights reserved.

\section{Introduction}

Diseases transmitted by arthropod vectors greatly impact human and animal health [1]. Among arthropod vectors, ticks are being considered as worldwide relevant vectors of diseasecausing pathogens such as Anaplasma phagocytophilum (human, equine and canine granulocytic anaplasmosis and tick-borne fever of ruminants), Borrelia spp. (Lyme disease and various borreliosis), tick-borne encephalitis virus (tick-borne encephalitis), louping ill virus (ovine encephalomyelitis), Crimean-Congo hemorrhagic fever virus (Crimean-Congo hemorrhagic fever), Francisella

* Corresponding autor at: Interdisciplinary Laboratory of Clinical Analysis of the University of Murcia (Interlab-UMU), University of Murcia, Espinardo, Spain.

E-mail address: marinelacontreras@gmail.com (M. Contreras). tularensis (tularemia), Rickettsia spp. (human and animal rickettsiosis), Omsk hemorrhagic fever virus (Omsk hemorrhagic fever), and Babesia spp. (canine and bovine babesiosis) [2-4].

In Spain, European roe deer (Capreolus capreolus) are one of the principal wild ungulates in terms of abundance $[5,6]$. Their number and distribution in the Iberian Peninsula have been expanding during the last decades and are usually distributed in potentially suitable habitats for ticks, which may facilitate the transmission of diseases that could be shared with other wild and domestic ungulates $[5,6]$. Studies of tick infestation in roe deer conducted in northwestern Spain showed that these animals are important hosts for Ixodes ricinus, [7]. Recently, Rayas et al. [8] found Rhipicephalus sanguineus and I. ricinus as the predominant tick species parasitizing roe deer in southwestern Spain serving as vehicle for the geographic distribution of these ticks and tick-borne diseases. 
Accordingly, serum samples from these animals revealed a $79 \%$ seroprevalence for Anaplasma spp as well as a $100 \%$ seroprevalence for Babesia spp. and Theileria spp. Furthermore, I. ricinus, R. sanguineus, Hyalomma marginatum, Hyaloma lusitanicum, Haemaphysalis punctate and Dermacentor marginatum were identified in the study area.

In addition, interactions between wildlife and livestock create significant risks for disease transmission causing huge economic losses and complicating the attempts of parasite control in domestic animals [9].

Due to the role of these wildlife species as reservoirs of different pathogens, their abundance and increasing population, it is necessary the development of control strategies. In the early $1990 \mathrm{~s}$, vaccines became available as a cost-effective and commercially alternative for cattle tick control that reduced the use of acaricides, and the problems associated with them such as selection of acaricide-resistant ticks, environmental contamination and contamination of milk and meat products with pesticide residues [10-13].

Vaccination with BM86, subolesin (SUB) and akirin (AKR) protective antigens in white tailed deer (Odocoileus virginianus) and red deer (Cervus elaphus) demonstrated that vaccination with vector protective antigens could be used as an alternative method for the control of tick infestations in deer to reduce tick populations and dispersal in regions where these animals are relevant hosts for these ectoparasites [14].

SUB and AKR are ortholog proteins in ticks and insects [15-17] that act as transcriptional regulatory factors affecting the expression of signal transduction and innate immune response genes $[15,18-20]$. SUB/AKR gene knockdown explains the effect on tick and insect physiology, development and gene expression $[15,19,21-23]$.

Experiments with recombinant SUB/AKR have shown the positive effect of vaccination on the control of several arthropod vectors including hard and soft ticks, mosquitoes, sand flies, poultry red mites and sea lice, and also the infection/ transmission of vector-borne pathogens $[14,24]$. Furthermore, recent vaccination experiments in rabbits, showed that the recombinant SUB/AKR chimera Q38 has an effect on the control of I. ricinus and Dermacentor reticulatus larvae by considering the cumulative effect on reducing tick survival and molting [25].

Roe deer was selected due their role in the maintenance of ticks and tick-borne pathogens $[7,8,26]$. Tick vaccines have not been previously tested in roe deer, but previous results suggested that Q38 might be a candidate universal antigen for the control of multiple arthropod ectoparasites and the pathogens they transmit in this wild ungulate. Recombinant SUB/AKR chimera (Q38) was selected for vaccination because the presence of conserved protective epitopes against different vector species [24]

The objective of this experiment was the characterization of the antibody response in roe deer immunized with recombinant Q38 and its effect on the control of tick infestation under field conditions.

\section{Material and methods}

\subsection{Vaccine formulations}

The recombinant SUB/AKR chimera Q38 was amplified from synthetic genes (JX193856) optimized for codon usage in Escherichia coli and cloned into the expression vector pET101 and expressed in E. coli strain BL21 using the Champion pET101 Directional TOPO Expression kit (Carlsbad, CA, USA). Recombinant proteins produced using this expression system were fused to Histidine tags for purification by affinity to $\mathrm{Ni}[22,24]$. Transformed
E. coli strains were induced with IPTG for $4.5 \mathrm{~h}$ to produce recombinant chimeric Q38 protein, which were purified to $>85 \%$ of total cell proteins by $\mathrm{Ni}$ affinity chromatography using $1 \mathrm{ml}$ HisTrap FF columns mounted on an AKTA-FPLC system (GE Healthcare, Piscataway, NJ, USA) in the presence of $7 \mathrm{M}$ urea lysis buffer. Recombinant antigens or saline control were adjuvated in Montanide ISA 50 V2 (Seppic, Paris, France) [25,27].

\subsection{Ethics statement}

Animal experiments in this study were conducted in strict accordance with the recommendations of the European Guide for the Care and Use of Laboratory Animals. This project was approved by the Regional Ministry of Environment and Territorial Planning for experimentation in animals in one of its reference stations of the roe deer, using standardized protocols for the handling of these animals under field conditions.

\subsection{Roe deer immunization with recombinant $\mathrm{Q} 38$}

Adult female and male roe deer (Capreolus capreolus) were captured with fix capture boxes randomly assigned to five fenced areas in Andalusian roe deer Reference Station ("El Picacho"). El Picacho is a mountain peak located in the Sierra del Aljibe in the province of Cadiz in Spain. This mountain area contains forests in which cork oaks, gall oaks and chestnuts abound. The fauna is represented by species such as the common deer, roe deer, red fox, genet, badger, eagles, griffon vulture, jay, falcons, owls and a large number of bird species. Of the fenced areas, four of them for vaccinated with the recombinant Q38 and one for control animals (Fig. 1). Roe deer were each immunized once a year, during the years 2015-2017, with $1 \mathrm{ml}$ vaccine (100 $\mu \mathrm{g}$ Q38 per dose) for three years (T1, T2 and T3) but not all the animals could be immunized in the third year, since some of them were not captured. Ten animals in total, from the different five fenced areas, were immunized intramuscularly with the recombinant Q38 and three animals, from the control area, were immunized with adjuvant/ saline alone. To characterize roe deer immune response to vaccination, blood samples were collected before each immunization (T1, $\mathrm{T} 2$ and T3) into sterile tubes and maintained at $4{ }^{\circ} \mathrm{C}$ until arrival at the laboratory. Sera were prepared and stored at $-20{ }^{\circ} \mathrm{C}$ after centrifugation of blood samples.

\subsection{Tick infestation levels}

Each year (July-October), infestation levels of adult fed females were determined at the time of vaccination as estimated infestation levels to avoid delaying the release of the animals and preventing them from becoming stressed [28]. Tick numbers per animal for all tick species were estimated as $0,30,150$ or 250 ticks/per animal. Roe deer were maintained in separate areas as regulated by local authorities to facilitate following of these animals. Due to difficulties in capturing wild roe deer, vaccinated and control animals were allocated to different fenced areas to facilitate following at least some of these animals. For analysis, the average tick infestation in Q38 vaccinated and control animals were compared using a Student's t-test at T2 and T3 ( $\mathrm{p}=0.05)$.

\subsection{Analysis of antibody response by ELISA}

An indirect ELISA test was performed to detect antibodies against Q38 protein in vaccinated and control roe deer serum samples collected at T1-T3 [24]. High absorption capacity polystyrene microtiter plates were coated with $100 \mu \mathrm{l}(0.01 \mu \mathrm{g} / \mathrm{ml}$ solution of purified recombinant proteins) per well in carbonate-bicarbonate buffer (Sigma-Aldrich). After an overnight incubation at $4{ }^{\circ} \mathrm{C}$, 


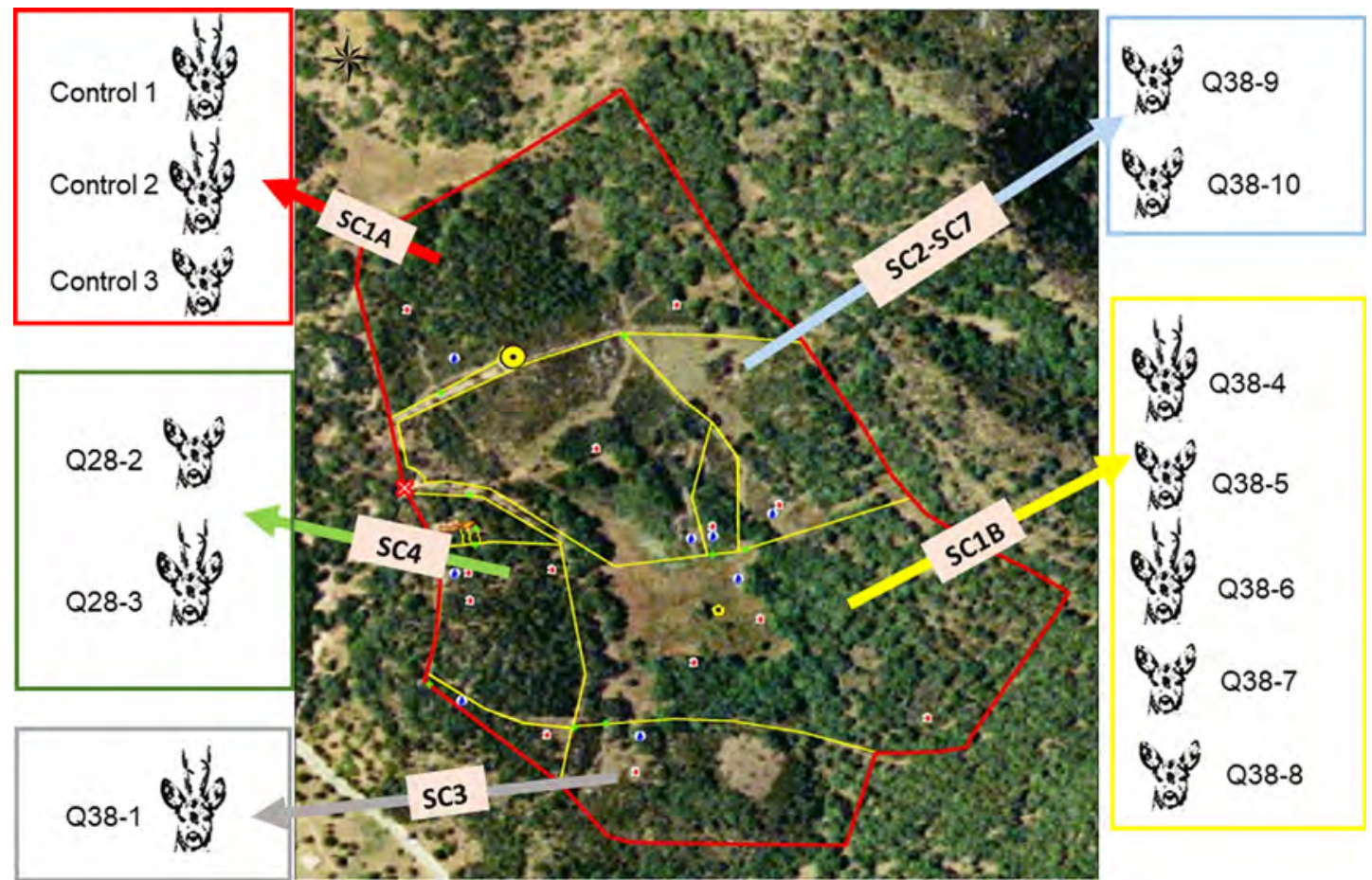

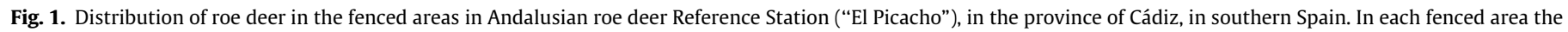
number of animals and their sex composition are shown in boxes.

coated plates were blocked with $100 \mu \mathrm{l} /$ well of blocking solution (5\% skim milk in PBS). Serum samples or PBS as negative control were diluted $(1: 100, v / v)$ in blocking solution and $100 \mu \mathrm{l} /$ well were added into duplicate wells of the antigen-coated plates. After one-hour incubation at $37 \circ \mathrm{C}$, the plates were washed three times with a washing solution (PBS containing 0.05\% Tween 20). Protein $\mathrm{G}$ horseradish-conjugated peroxidase (Bio-Rad Laboratories, Hercules, CA) was added ( $100 \mu \mathrm{l} /$ well $)$ at a dilution of $2.5 \mu \mathrm{g} / \mathrm{ml}$ in PBST and incubated at $37^{\circ} \mathrm{C}$ for $1 \mathrm{hr}$. After revealing, the reaction was stopped with $50 \mu \mathrm{l} /$ well of sulfuric acid $\left(\mathrm{H}_{2} \mathrm{SO}_{4} ; 3 \mathrm{~N}\right)$, and optical density (OD) was measured in a spectrophotometer at $450 \mathrm{~nm}$. Antibody titers in vaccinated and control roe deer were expressed as the OD450nm (OD roe deer sera-OD PBS control) and compared between vaccinated and control groups by One-way ANOVA test $(p=0.05)$ (https://www.socscistatistics.com/tests/anova/default2. aspx).

\section{Results and discussion}

\subsection{Characterization of the antibody response in vaccinated roe deer.}

The antibody response against Q38 in vaccinated roe deer increased after successive immunizations. All the animals were immunized with at least two doses of the recombinant Q38 and after the first vaccination, antibody titers were significantly higher in vaccinated than in control roe deer (Fig. 2A).

Other studies have shown that two vaccine doses may be sufficient to developed antigen-specific antibodies in cattle and other hosts vaccinated with SUB or AKR and antibody levels remained similar or increased after the second immunization [14,29,30]. The results after vaccination suggested that roe deer also develop a specific antibody response after immunization with two vaccines doses, even if these are done once a year (Fig. 2A). In animals immunized three times it is shown that the antibody titers are maintained for the whole year until the next immunization, which suggested that the protective response is maintained during the study time [13].

\subsection{Control of field tick infestations in roe deer}

Since this is a study under field conditions and due to limitations in animal captures, the sample size of the study is low. Additionally, tick numbers per animal do vary between different time points. However, these results show an approximation of the effectiveness of the vaccine in wildlife.

The number of ticks was lower in the group of animals vaccinated with recombinant Q38 compared to the control group (Fig. 2B). Due to the fact that randomly selected control animals had higher tick infestations than roe deer included in vaccinated groups at T1 (Fig. 3), the analysis was focused on the effect of the vaccine at $\mathrm{T} 2$ and $\mathrm{T} 3$ by comparing control and vaccinated groups (Fig. 2B). Although at T3 the number of ticks tend to increase, this increase was smaller in the group of vaccinated animals when compared to the control group (Fig. 2B). The tick species collected from the vegetation of the fenced areas and which were likely infesting the animals included $H$. marginatum, $H$. lusitanicum, $R$. bursa and I. ricinus that have been previously identified in this study area [8]. These tick coinfestations are commonly found in other wild ungulates with the same geographical distribution [31]. Furthermore, the efficacy of the Q38 antigen was extended to include new tick species and the effect on different developmental processes in several important arthropod vectors, [24] thus supporting that this antigen might be a candidate universal antigen for the control of multiple tick species that can be found on the same host.

The experiment resembled the real conditions in the field, considering factors such as tick infestation rate, single or multiple tick species, tick hosts involved and tick generations per year. Under these conditions, the effect of the vaccine in reducing field tick populations would have to be determined under different scenarios. Previous vaccination trials showed efficacy of Q38 for the control of I. ricinus, D. reticulatus and Rhipicephalus microplus species $[24,25,27]$. In this experiment we did not classify the ticks collected from infested roe deer, but the results suggested that Q38 may be effective for the control of other tick species such as Hya- 
A

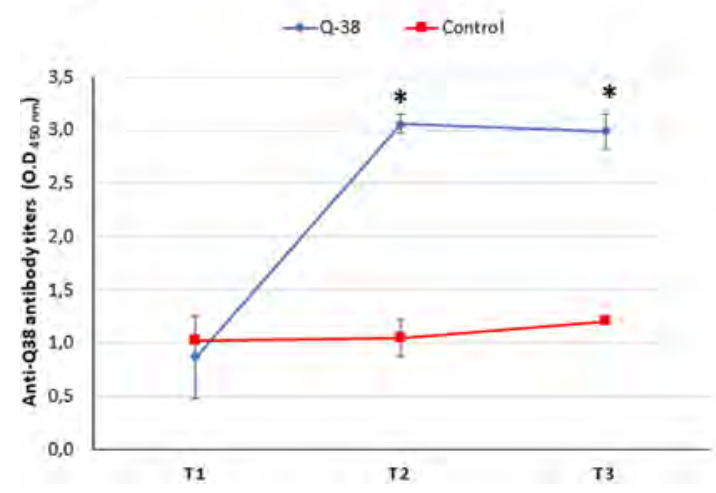

B

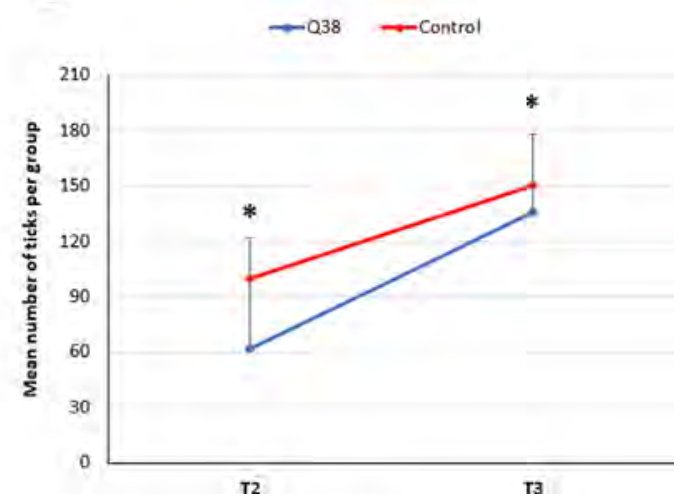

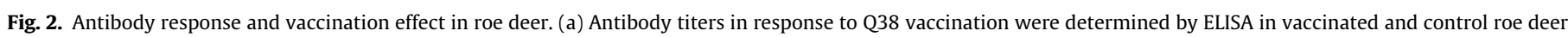

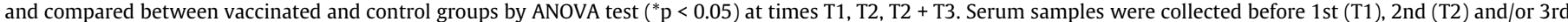

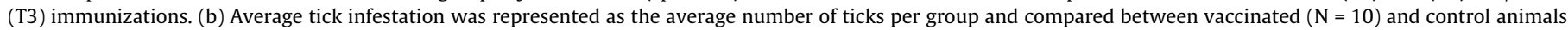
$(\mathrm{N}=3)$ at T2 and T3 using a Student's $t$-test $\left({ }^{*} \mathrm{p}<0.05\right)$.
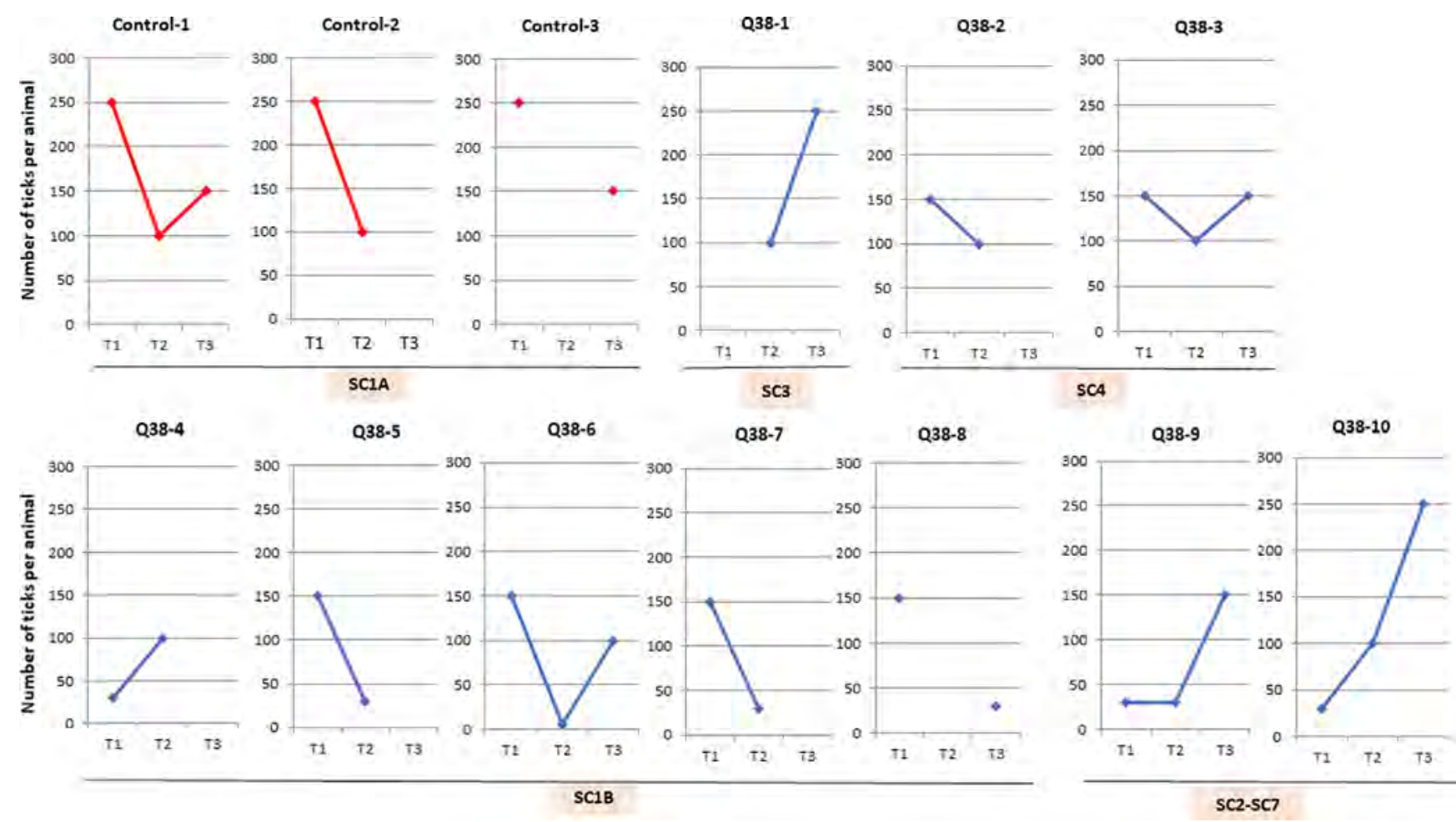

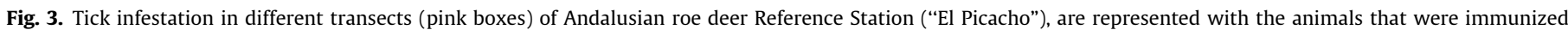

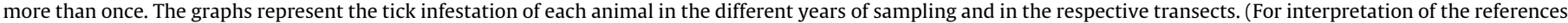
to colour in this figure legend, the reader is referred to the web version of this article.)

lomma spp. and encouraged new experiments to evaluate the effect of arthropod vector protective antigens on wild host tick infestations.

\section{Declaration of Competing Interest}

The authors declare that they have no known competing financial interests or personal relationships that could have appeared to influence the work reported in this paper.

\section{Acknowledgements}

This research has been developed within the agreement of collaboration between SaBio (Animal health and Biotechnology) from
IREC (Instituto de Investigación en Recursos Cinegéticos) and Agencia de Medio Ambiente y Agua de Andalucía (Consejería de Agricultura, Ganadería, Pesca y Desarrollo Sostenible-Junta de Andalucía. Marinela Contreras is funded by the Ministerio de Ciencia, Innovación y Universidades, Spain, grant FJC-2018-038277-I.

\section{References}

[1] Jones KE, Patel NG, Levy MA, Storeygard A, Balk D, Gittleman JL, et al. Globaltrends in emerging infectious diseases. Nature 2008;451:990-4.

[2] de la Fuente J, Estrada-Peña A, Venzal JM, Tocan KM. Sonenshine DE Overview: ticks as vectors of pathogens that cause disease in humans and animals. Front Biosci 2008;1:6938-46.

[3] Estrada-Peña A, Ayllón N, de la Fuente J. Impact of climate trends on tick-borne pathogen transmission. Front Physiol 2012;3:64.

[4] Beugnet F, Marié JL. Emerging arthropod-borne diseases of companion animalsin Europe. Vet Parasitol 2009;163:298-305. 
[5] Geist V. Deer of the world: their evolution, behavior, and ecology. Mechanicsburg: Stackpole Books; 1998.

[6] Morrondo MP, Pérez-Creo A, Prieto A, Cabanelas E, Díaz-Cao JM, Arias MS, et al Prevalence and distribution of infectious and parasitic agents in roe deer from Spain and their possible role as reservoirs. Ital J Anim Sci 2017;16(2):266-74.

[7] Vázquez L, Panadero R, Dacal V, Pato FJ, López C, Díaz P, et al. Tick infestation (Acari: Ixodidae) in roe deer (Capreolus capreolus) from northwestern Spain: population dynamics and risk stratification. Exp Appl Acarol. 2011 Apr;53 (4):399-409. https://doi.org/10.1007/s10493-010-9403-7.

[8] Rayas E, Fernández-Salguero P, Prieto A, Remesar S, San José C, Talavera V, et al. Estudio de prevalencia de agentes patógenos en corzo (Capreolus capreolus) transmitidos por garrapatas en el área cinegética de alcornocales. Almoraima. Revista de Estudios Campo gibraltareños 2018;49:25-32.

[9] Barasona JA, VerCauteren KC, Saklou N, Gortazar C, Vicente J. Effectiveness of cattle operated bump gates and exclusion fences in preventing ungulate multihost sanitary interaction. Prev Vet Med 2013;111:42-50.

[10] de la Fuente J, Kocan KM. Strategies for development of vaccines for control of ixodid tick species. Parasite Immunol 2006;28:275-83.

[11] Willadsen P. Tick control: thoughts on a research agenda. Vet Parasitol 2006;138:161-8.

[12] de la Fuente J, Almazán C, Canales M, Pérez de la Lastra JM, Kocan KM, Willadsen P. A ten-year review of commercial vaccine performance for control of tick infestations on cattle. Anim Health Res Rev 2007;8:23-8.

[13] de la Fuente J, Contreras M. Tick vaccines: current status and future directions. Expert Rev Vaccines 2015;14:1367-76.

[14] Carreón D, de la Lastra JM, Almazán C, Canales M, Ruiz-Fons F, Boadella M, et al. Vaccination with BM86, subolesin and akirin protective antigens for the control of tick infestations in white tailed deer and red deer. Vaccine 2012;30 (2):273-9.

[15] de la Fuente J, Almazán C, Blas-Machado U, Naranjo V, Mangold AJ, Blouin EF, et al. The tick protective antigen, 4D8, is a conserved protein involved in modulation of tick blood ingestion and reproduction. Vaccine 2006;24:4082-95.

[16] Galindo RC, Doncel-Pérez E, Zivkovic Z, Naranjo V, Gortazar C, Mangold AJ, et al. Tick subolesin is an ortholog of the akirins described in insects and vertebrates. Dev Comp Immunol 2009;33:612-7.

[17] Mangold AJ, Galindo RC, de la Fuente J. Response to the commentary of D. Macqueen on: Galindo RC, Doncel-Pérez E, Zivkovic Z, Naranjo V, Gortazar C, Mangold AJ, et al. Tick subolesin is an ortholog of the akirins described in insects and vertebrates . Dev Comp Immunol 2009; 33:878-9

[18] Goto A, Matsushita K, Gesellchen V, El Chamy L, Kuttenkeuler D, TakeuchiO, et al. Akirins are highly conserved nuclear proteins required for NF-kappaBdependent gene expression in drosophila and mice. Nat Immunol 2008; 9:97104.
[19] de la Fuente J, Maritz-Olivier C, Naranjo V, Ayoubi P, Nijhof AM, Almazán C, et al. Evidence of the role of tick subolesin in gene expression. BMC Genomics 2008;9(372)

[20] Nowak SJ, Aihara H, Gonzalez K, Nibu Y, Baylies MK. Akirin links twistregulated transcription with the Brahma chromatin remodeling complex during embryo-genesis. PLoS Genet 2012;8:e1002547.

[21] Naranjo N, Ayllón N, Pérez de la Lastra JM, Galindo RC, Kocan KM, Blouin EF, Mitra R, Alberdi P, Villar M, de la Fuente J. Reciprocal regulation of NF-kB (Relish) and Subolesin in the tick vector,Ixodes scapularis. PLoS ONE 2013;8: e65915.

[22] de la Fuente J, Almazán C, Naranjo V, Blouin EF, Meyer JM, Kocan KM. Autocidal control of ticks by silencing of a single gene by RNA interference. Biochem Biophys Res Commun 2006;344:332-8.

[23] Kocan KM, Zivkovic Z, Blouin EF, Naranjo V, Almazán C, Mitra R, et al. Silencing of genes involved in Anaplasma marginale-tick interactions affects the pathogen developmental cycle in Dermacentor variabilis. BMC Dev Biol 2009;9:42.

[24] Moreno-Cid JA, Pérez de la Lastra JM, Villar M, Jiménez M, Pinal R, EstradaPeña, et al. Control of multiple arthropod vector infestations with subolesin/ akirin vaccines. Vaccine 2013; 31:1187-96

[25] Contreras M, de la Fuente J. Control of Ixodes ricinus and Dermacentor reticulatus tick infestations in rabbits vaccinated with the Q38 Subolesin/ Akirin chimera. Vaccine 2016;34(27):3010-3.

[26] de la Fuente J, Ruiz-Fons F, Naranjo V, Torina A, Rodríguez O, Gortázar C. Evidence of Anaplasma infections in European roe deer (Capreolus capreolus) from southern Spain. Res Vet Sci 2008;84(3):382-6.

[27] Merino M, Antunes S, Mosqueda J, Moreno-Cid JA, Pérez de la Lastra JM, Rosario- Cruz R, et al. de la Fuente J. Vaccination with proteins involved in tickpathogen interactions reduces vector infestations and pathogen infection. Vaccine 2013;31:5889-96.

[28] Huber N, Vetter SG, Evans AL, Kjellander P, Küker S, Bergvall UA, et al. Quantifying capture stress in free ranging European roe deer (Capreolus capreolus). BMC Vet Res 2017;13:127.

[29] Canales M, Naranjo V, Almazán C, Molina R, Tsuruta SA, Szabó MP, ManzanoRoman R, Pérez de la Lastra JM, Kocan KM, Jiménez MI, Lucientes J, Villar M, de la Fuente J. Conservation and immunogenicity of the mosquito ortholog of the tick protective antigen, subolesin. Parasitol Res 2009; 105:97-111.

[30] de la Fuente J, Almazán C, Blouin EF, Naranjo V, Kocan KM. Reduction of tick infections with Anaplasma marginale and A. phagocytophilum by targeting the tick protective antigen subolesin. Parasitol Res 2006;100:85-91.

[31] Ruiz-Fons F, Fernández de Mera IG, Acevedo P, Höfle U, Vicente J, de la Fuente Gortazár C. Ixodid ticks parasitizing Iberian red deer (Cervus elaphus hispanicus) and European wild boar (Sus scrofa) from Spain: geographical and temporal distribution. Vet Parasitol 2006;140:133-42. 